Dutmie, E. S. (1952). J. gen. Microbiol. 7, 320-326.

\title{
Variation in the Antigenic Composition of Staphylococcal Coagulase
}

\author{
By E. S. DUTHIE \\ Royal South Hants Hospital, Southampton
}

\begin{abstract}
SUMMARY: Four different antigenic types of coagulase were identified. Antisera were prepared in rabbits against three of these, and a specific antiserum against the fourth was found in a normal human. The coagulases of all but two of the human strains examined were inhibited by one or other of two of these antisera and in a few cases by both; in addition antibodies of the same type were present in the sera of the majority of a group of normal adults. The coagulases produced by thirty-five animal strains were inhibited by the other two antisera, but further work is needed on the coagulases found in animal strains.
\end{abstract}

Several workers (Lominski \& Roberts, 1946; Bekker, 1947; Tager \& Hales, 1948; Rammelkamp, Hezebicks \& Dingle, 1950) have described antibodies to staphylococcal coagulase in normal sera and plasma. By cross-neutralization tests with the sera of a group of $\mathbf{1 4 8}$ normal individuals against the coagulases of different staphylococcal strains, Rammelkamp et al. (1950) found that these coagulases fell into three different antigenic types. Many sera inhibited more than one of the three coagulases finally selected for intensive study, but there was usually a wide variation between the titres obtained in each serum, and some sera were almost specific for an individual coagulase. Immunization experiments in monkeys showed that two of the coagulases isolated were very nearly distinct antigenically, but the third type appeared to be related to the other two.

The development of a simple and reliable method for the production of antibodies in rabbits against coagulase (Duthie \& Lorenz, 1952) made it possible to investigate these claims more thoroughly. The present paper reports this work, together with a limited survey of the antibodies to staphylococcal coagulase and $\alpha$-toxin present in human sera from a small group of laboratory workers.

\section{METHODS}

Strains. For the isolation of good coagulase-producing colonies, strains were plated out on nutrient agar containing sterile fibrinogen and human plasma. Strains which did not show a zone of clotted fibrin around each colony were not suitable for study, although such strains might give a positive slide test with plasma. Suitable colonies were either grown immediately in the fluid medium or were stored as stab cultures in nutrient agar at $4^{\circ}$.

Preparation and assay of coagulase for antigenic typing. Cultures were made in $25 \mathrm{ml}$. conical flasks containing $2 \mathrm{ml}$. of digest broth supplemented by $\mathbf{0 . 3} \%$ bovine albumin (Armour). They were shaken on a tilted gramophone turntable at $37^{\circ}$ until fully grown, when the supernatants were separated by centrifuging. For assay $0.1 \mathrm{ml}$. of falling dilutions of the supernatants, 
usually at $1 / 5,1 / 10,1 / 30$ and $1 / 90$ in veronal buffer at $\mathrm{pH} 7 \cdot 0$, were mixed with $0.1 \mathrm{ml}$. of normal rabbit serum, diluted to $1 / 5$, in tubes $5 \times 0.6 \mathrm{~mm}$. After $30 \mathrm{~min}$. on the bench $0.2 \mathrm{ml}$. of a mixture of $0.1 \%(\mathrm{w} / \mathrm{v})$ bovine or human fibrinogen and fresh rabbit plasma $0.5 \%(\mathrm{v} / \mathrm{v})$ was added to each tube and the rack was incubated for $1 \mathrm{hr}$. at $37^{\circ}$. One drop of a $5 \%(\mathrm{w} / \mathrm{v})$ suspension of 'Filter-cel' (Johns-Manville) was added to each tube and, after shaking, the rack was placed for a short time in the refrigerator before reading. Tubes might show a clot, a broken clot, gross floccules, finer floccules, or floccules just distinguishable from those in the control tubes. The titre of the coagulase chosen for use in the final test was taken as that giving either a broken clot or gross floccules and sometimes both strengths were used; these values could be readily determined with practice.

Antigenic typing of coagulase. In this test each coagulase was at that dilution which in the preliminary titration gave either a broken clot or gross floccules i.e. at about 10-20 M.C.D./ml. (M.c.D. defined below) Antisera and serum controls were diluted 1/5 and mixed with the coagulases at the levels chosen and held for $30 \mathrm{~min}$. at room temperature. An equal volume of the fibrinogen + plasma mixture was then added and after $1 \mathrm{hr}$. at $37^{\circ}$ 'Filter-cel' added and the tubes read as before.

Purified coagulases were stable during the test period, but many fresh preparations contained the coagulase in an unstable form; although the supernatants had been stored in the cold, the titres varied between the preliminary titration and typing. In such cases assays were repeated and correspondingly lower dilutions used.

Preparation of antisera. This was essentially as described in the previous work (Duthie \& Lorenz, 1952). The subcutaneous injection at fortnightly intervals of $10 \mathrm{mg}$. of partially purified high titre coagulase adsorbed on $3 \mathrm{mg}$. $\mathrm{AlPO}_{4}$, gave relatively good titres in 8-10 weeks, which could be maintained or even raised by subsequent injections.

Antibody assay against purified coagulase. This was as previously described (Duthie \& Lorenz, 1952) except that veronal buffer was used as a diluent. Sera were not inactivated, but heparin $2-5$ units $/ \mathrm{ml}$. was added after separation, and the sera held at $37^{\circ}$ to destroy thrombin. The mixtures consisted of $0.1 \mathrm{ml}$. of falling dilutions of serum and $0.1 \mathrm{ml}$. of coagulase $(20 \mathrm{M} . \mathrm{C} . \mathrm{D} . / \mathrm{ml}$.) which were left at room temperature for $30 \mathrm{~min}$. after which $\mathbf{0 \cdot 2} \mathrm{ml}$. of the fibrinogen-plasma mixture was added and the tubes incubated for $1 \mathrm{hr}$. at $37^{\circ}$. One drop of $5 \%$ 'Filter-cel' was added to each tube before reading. The reciprocal of the serum dilution just sufficient to allow minimal clotting was taken as the titre of the serum expressed in units. The M.C.D. or minimal clotting dose of the purified coagulase was that amount of coagulase $/ \mathrm{ml}$. which, when mixed with $1 \mathrm{ml}$. of plasma fibrinogen and incubated at $37^{\circ}$ for $\mathrm{l} \mathrm{hr}$., gave minimal flocculation after the addition of one drop of 'Filtercel' to $0.4 \mathrm{ml}$. of the mixture. This standard is variable since it depends on the stability of a particular fibrinogen preparation; in practice certain sera were stored frozen and the standard coagulases were kept as lyophil dried powders. $\alpha$-Antitoxin was determined at the $1 / 10$ unit level in the usual manner. 


\section{RESULTS}

A preliminary survey of some fifty strains from human lesions showed that with few exceptions the coagulases were completely inhibited by an antiserum, diluted 1/5, prepared against the 'Newman' strain coagulase previously described. The exceptions were in part inhibited by the antiserum, and a reduction in the concentration of the coagulase below the level normally used gave complete inhibition. At this stage ten strains of animal origin were received from Mr Proom, and it was found that many of these produced a coagulase which was not inhibited by the 'Newman' antiserum. At the same time strain 104 was received from Dr Tager, and since its coagulase was not inhibited it was decided to immunize rabbits with coagulase from strain 104 and from one of Mr Proom's strains, CN 59. For clarity the coagulase from the 'Newman' strain (human origin) will be referred to as coagulase A, that from CN 59 (bovine origin) as B, and that from Tager's 104 (human origin) as $\mathrm{C}$. The corresponding antisera are named antiserum $\mathbf{A}, \mathbf{B}$ and $\mathbf{C}$.

All these strains produced a stable coagulase in high titre and it was possible to purify the material by precipitation with $\mathrm{CdSO} 4$ followed by dialysis against $0.01 \mathrm{~N}-\mathrm{HCl}$ (Duthie \& Lorenz, 1952). Injection of this material into rabbits gave good titres and cross-neutralization tests, shown by Table 1, were reasonably specific. In the final stages of the study it was found that a number of staphylococcal strains, freshly isolated from superficial infections in humans, produced a fourth coagulase which was not completely inhibited by any of the antisera A, B and C, and only in part by antiserum A. Attempts to prepare an antiserum in rabbits were unsuccessful, but as the majority of human sera contained at least five units of antibody to this coagulase/ml. there was little difficulty in finding one which had 100 units $/ \mathrm{ml}$. with little or none against any of the other coagulases. This serum, antiserum D, also appears in Table $\mathbf{1}$.

Table 1. Cross-neutralization of coagulases $A, B, C$ and $D$ by their respective antisera

\begin{tabular}{|c|c|c|c|c|c|c|c|c|c|c|c|c|}
\hline & & & & & & ntiserur & & & & & & \\
\hline & & A & & & B & & & C & & & D & \\
\hline & & & & & Serur & dilutic & & & & & & \\
\hline lase & 5 & 10 & 20 & 5 & 10 & 20 & 5 & 10 & 20 & 5 & 10 & 20 \\
\hline $\mathbf{A}$ & - & - & - & ++ & +++ & $\mathrm{BC}$ & $\mathrm{BC}$ & $\mathrm{BC}$ & $\mathrm{BC}$ & $\mathbf{B C}$ & BC & BC \\
\hline B & BC & BC & BC & - & - & - & $\mathrm{C}$ & C & C & $\mathbf{C}$ & C & C \\
\hline C & ++ & +++ & BC & $+t+$ & +++ & +++ & - & - & - & $\mathrm{BC}$ & $\mathrm{BC}$ & BC \\
\hline D & +++ & $++t$ & BC & $\mathrm{BC}$ & BC & $\mathrm{BC}$ & $\mathrm{BC}$ & BC & $\mathrm{BC}$ & - & - & - \\
\hline
\end{tabular}

All sera, including the human serum D, had titres of between 60 and $100 \mathrm{units} / \mathrm{ml}$. and at the dilution of $1 / 5$ employed in typing other coagulases there was good specificity for the four antigens together with a large excess 
of antibody. Sera were stored frozen, since a preservative could not be added without risk of harming the coagulase in the test. Under these conditions there was some deterioration in potency, which was never more than $c .30 \%$ in several months.

\section{Antigenic pattern of the coagulase from different strains}

Apart from the coagulases first tested with antiserum $\mathbf{A}$, the coagulases produced by eighty-five strains from infections in fifty humans and thirty-five animals (cows and sheep) were tested with these antisera with the results shown in Table 2. The fifty human strains are probably representative, since they were in all but one case, i.e. Tager's strain 104, chosen from a random series of staphylococcal infections, mostly of a superficial nature, encountered in hospital practice. Coagulases of five strains were inhibited equally by two different antisera, three by $\mathbf{A}$ and $\mathrm{C}$ and two by $\mathrm{A}$ and D. Six were completely inhibited only by antiserum $\mathbf{D}$ and partly inhibited by $\mathbf{A}$, while the remainder were inhibited by antiserum A. Thus some $86 \%$ of these human strains produced a coagulase which was inhibited by antibodies to coagulase $\mathbf{A}$.

Table 2. Inhibition of the coagulases produced by eighty-five staphylococcal strains of human and animal origin

\begin{tabular}{cccc} 
& \multicolumn{3}{c}{ Origin of strains inhibited by } \\
Antisera & $\overbrace{\text { Man }}$ & Cow & Sheep \\
A & 38 & 11 & 1 \\
B & - & 2 & 1 \\
C & 1 & 5 & 10 \\
D & 6 & - & - \\
A and C & 3 & 5 & - \\
A and D & 2 & - & - \\
Totals & 50 & 23 & 12
\end{tabular}

The thirty-five animal strains were from three sources. Fifteen strains isolated locally by Mr J. C. Francis from cases of bovine mastitis all produced coagulases which were inhibited by antiserum $A$ and four were in addition inhibited by antiserum $\mathrm{C}$. The remaining twenty were stock laboratory strains received from Mr Foggie and Mr Proom. One of these, a strain of ovine origin, produced a coagulase only inhibited by antiserum $\mathbf{A}$; while another of bovine origin produced a coagulase inhibited by both $\mathrm{A}$ and $\mathrm{C}$ antisera. The coagulases produced by the remaining eighteen strains (bovine and ovine) were inhibited by antisera B or C. Apart from these eighty-five strains there were four, two of human origin and two of bovine origin, which were partially inhibited only by antiserum $\mathbf{A}$, and which in consequence were untypable.

\section{Antibodies in normal human sera}

Since a previous survey (Duthie \& Lorenz, 1952) showed that antibodies against type $A$ coagulase were present in the sera of the majority of a group of twenty-five laboratory workers, it was decided to repeat these tests measuring 
in addition antibodies against $B, C$ and $D$ type coagulases and against $\alpha$-toxin. Although six of the twenty-five sera now tested were from individuals other than those measured 6 months previously, the distribution of the anti-A coagulase levels was very similar (Table 3). Thus ten had between 0 and $1 \mathrm{unit} / \mathrm{ml}$., eleven had 2-10 units/ml. and four had 15-80 units $/ \mathrm{ml}$. The nineteen persons measured previously showed little or no change in their serum levels except at the 0-1 unit level which is difficult to read and which has shown discrepancies in the past, either because of residual traces of thrombin or because of the instability of coagulase in unbuffered and undiluted serum. The addition of $2 \mathrm{M}-\mathrm{KH}_{2} \mathrm{PO}_{4}$ to a final concentration of about $0.04 \mathrm{M}$ has greatly improved the consistency of these low-level readings.

Table 3. Estimation of anticoagulase and $\alpha$-antitoxin titres in units/ml. in the sera of twenty-five laboratory workers

\begin{tabular}{|c|c|c|c|c|}
\hline \multirow[b]{2}{*}{ Serum no. } & \multicolumn{3}{|c|}{ Anticoagulase } & \multirow[b]{2}{*}{$\alpha$-Antitoxin } \\
\hline & Anti-A & Anti-C & Anti-D & \\
\hline 1 & 1 & 0 & 7 & $0 \cdot 8$ \\
\hline 2 & 2 & 1 & $2 \cdot 5$ & 0 \\
\hline 3 & 30 & 20 & 0 & 1.0 \\
\hline 4 & 10 & 10 & 50 & $1 \cdot 5$ \\
\hline 5 & 5 & 0 & 10 & $1 \cdot 0$ \\
\hline 6 & $2 \cdot 5$ & 5 & $\mathbf{5}$ & $1 \cdot 6$ \\
\hline 7 & 5 & 0 & 15 & $1 \cdot 0$ \\
\hline 8 & 2 & 0 & 3 & 0.5 \\
\hline $\mathbf{9}$ & 15 & 0 & 50 & $1 \cdot 5$ \\
\hline 10 & 10 & 0 & 10 & $2 \cdot 0$ \\
\hline 11 & 15 & 10 & 80 & 0.5 \\
\hline 12 & 1 & 0 & 10 & 0 \\
\hline 13 & 2 & 0 & 120 & 0.4 \\
\hline 14 & 0 & 5 & 1 & $0 \cdot 4$ \\
\hline 15 & 1 & 0 & 1 & 0.5 \\
\hline 16 & $\mathbf{1}$ & 10 & 1 & $0 \cdot 5$ \\
\hline 17 & 0 & 7 & 0 & 0 \\
\hline 18 & 10 & 15 & 25 & 0.5 \\
\hline 19 & 2 & 0 & 5 & $1 \cdot 6$ \\
\hline 20 & 1 & 0 & 15 & $4 \cdot 0$ \\
\hline 21 & 0 & 2 & 2 & 0.5 \\
\hline 22 & 1 & 2 & 7 & 0.5 \\
\hline 23 & 1 & 2 & 15 & $0 \cdot 4$ \\
\hline 24 & 80 & 10 & 40 & $1 \cdot 0$ \\
\hline 25 & 2 & 0 & 15 & 0 \\
\hline
\end{tabular}

Only one of the twenty-five sera contained antibody against coagulase B, and as this antigen does not appear to be present in the coagulases produced by human strains, antibody B has not been included in Table 3. The antibodies varied widely between the sera, there being no relation between the levels of the three antibodies in different sera, nor did any anticoagulase bear any relation to the $\alpha$-antitoxin level. 


\section{DISCUSSION}

Four antigenically distinct types of coagulase have been encountered and it is likely that further search would reveal others, since the relatively crude method used in these experiments was intended to obscure possible subgroups. The existence of strains whose coagulase is inhibited by each of two antisera such as $\mathbf{A}$ and $\mathbf{C}$ or $\mathbf{A}$ and $\mathbf{D}$ suggests a common antigenic pattern to $\mathbf{A}$ and $\mathbf{C}$ and $\mathbf{A}$ and $\mathbf{D}$ which is hidden by other and more specific antigens, and this is borne out by Table 1 in which antigens $C$ and $D$ are partly inhibited by antiserum A.

More important is the finding that the coagulase of practically all the human strains examined is inhibited by antiserum $\mathrm{A}$ or $\mathrm{D}$ and mainly by the former. The high antibody titre of many human sera against these two antigens is possibly due to previous staphylococcal infections, though we have as yet no proof that these antibodies play any part in resistance. Of the twenty-five normal sera examined three giving the lowest titres against coagulase $\mathbf{A}$ came from the only individuals in the group who had suffered from staphylococcal infections in the past 12 months. Sera from a number of individuals with recurrent staphylococcal infections have in general had low antibody titres, but there have been two exceptions to this, and immunization experiments now in progress may help to decide if raising the antibody level in this type of infection is of value.

The position of the other antigens $\mathrm{B}$ and $\mathrm{C}$ is more doubtful since, apart from Tager's 104 strain of human origin, the only coagulases found which were inhibited only by either antiserum B or C, have come from stock strains of animal origin. The freshly isolated bovine strains examined produced coagulase which was completely inhibited by antiserum $\mathbf{A}$ and in part by antiserum $\mathrm{C}$, as did some human strains, and it is not impossible that cultural conditions might change such strains into those producing coagulase $\mathrm{C}$ only. Until a large number of freshly isolated animal strains can be examined the role of these antigens in infection must remain in doubt.

It has unfortunately not been possible to compare the coagulase types found with those used by Rammelkamp et al. (1950), and it is always possible that they do not correspond with those used in the present studies. Each of the four types of coagulase found may consist of a number of different antigens, some of which are common to other coagulases. If this is the case then the classification which emerges in any study will be determined by the antigenic pattern of the first member studied. One important result of these studies is to provide two master strains and hence two master sera for the majority of staphylococcal coagulases, and it is hoped to use these for the investigation of the prevention of recurring staphylococcal infections by active immunization with the human type coagulases $\mathbf{A}$ and $\mathbf{D}$.

My thanks are due to Dr C. H. Lack, Mr H. Proom, Dr M. Tager and Mr A. Foggie for staphylococcal strains. In addition, I wish to thank Mr J. C. Francis for animal strains and sera, the laboratory staff of the hospital for providing me with their sera, and Miss Sheila Isherwood for her valuable help. The work was made possible by a research grant from the South West Metropolitan Regional Hospital Board. 


\section{REFERENCES}

Bekker, J. H. (1947). Studies on staphylocoagulase. II. Antistaphylocoagulase in human serum. Antonie van Leeuwenhoek J. Microbiol. Serol. 13, 128.

Duthie, E. S. \& Lorenz, L. (1952). Staphylococcal coagulase: mode of action and antigenicity. J. gen. Microbiol. 6, 95.

Hale, J. H. \& Sirtit, W. (1945). The influence of coagulase on the phagocytosis of staphylococci. Brit. J. exp. Path. 26, 209.

Lominski, I. \& Roberts, G. B. (1946). A substance in human serum inhibiting staphylocoagulase. J. Path. Bact. 58, 187.

Rammelkamp, C. H., Hezebicks, M. M. \& Dingle, J. H. (1950). Specific coagulases of Staphylococcus aureus. J. exp. Med. 91, 295.

Sмith, W., Hale, J. H. \& Smith, M. M. (1947). The role of coagulase in staphylococeal infections. Brit. J. exp. Path. 28, 57.

Tager, M. \& Hales, H. B. (1948). Differences in the resistance of human plasmas to staphylocoagulase. Yale J. Biol. Med. 21, 91.

(Received 31 March 1952) 